$\begin{array}{cc}\text { ACADEMIA ROMÂNĂ } & \text { Rev. Roum. Chim., } \\ \text { Revue Roumaine de Chimie } & \text { 2020.65(11), 1031-1044 } \\ \text { http://web.icf.ro/rrch/ } & \text { DOI: 10.33224/rrch.2020.65.11.08 }\end{array}$

\title{
MOLECULAR DESCRIPTORS OF NEURAL NETWORKS WITH CHEMICAL SIGNIFICANCE
}

\author{
Sourav MONDAL, ${ }^{\mathrm{a}, *}$ Nilanjan $\mathrm{DE}^{\mathrm{b}}$ and Anita $\mathrm{PAL}^{\mathrm{c}}$ \\ ${ }^{a, c}$ Department of mathematics, National Institute of Technology Durgapur, West Bengal-713209, India \\ ${ }^{\mathrm{b}}$ Department of Basic Sciences and Humanities (Mathematics), Calcutta Institute of Engineering and Management, \\ Kolkata-700040, India
}

The probabilistic neural networks (PNNs) are now being analysed to fix a variety of challenges in the diverse fields of science and technology. In chemical graph theory, there are several tools, such as polynomials, functions, etc. that can be used to characterize different network properties. The neighborhood M-polynomial (NM) is one of those that yields neighborhood degree sum based topological indices in a manner that is less time consuming than the usual approach. In this work, the NM-polynomial of 3-layered and 4-layered probabilistic neural networks are derived. Further, some neighborhood degree sum based topological indices are computed from those polynomials. Applications of the present work are interpreted by investigating the chemical importance of the indices. Some structure property models are derived. The graphical representations of the results are also reported.

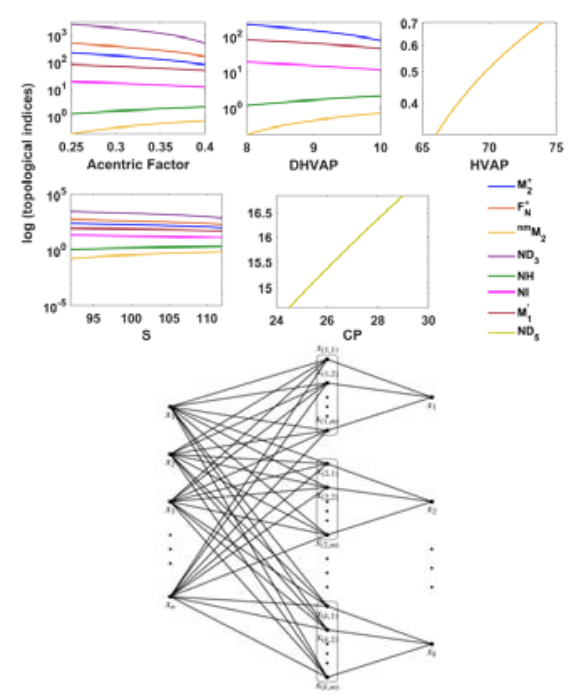

\section{INTRODUCTION}

Throughout this work, we consider connected graph without any loops and parallel edges. Let $\Omega$ be a simple connected graph having $V(\Omega)$ and $E(\Omega)$ as node set and edge set, respectively. The degree of a node $v$ of $\Omega$, denoted by $\kappa_{v}$, is the total number of edges incident to the node $v$ in $\Omega$. The degree sum of all nodes adjacent to $v$ in $G$ is denoted by $\tau_{v}$, i.e., $\tau_{v}=\sum_{\text {we } N_{v}} \kappa_{v}$, where $N_{v}$ is the collection of all nodes adjacent to $v$. The symbol $\tau_{v}$ is known as the neighborhood degree sum of $v$.
Graph theory offers the chemist and information scientist with a lot of excellent tools, such as topological matrices, algebraic polynomials and topological indices (or molecular descriptors). Such resources create a strong link between chemical graphs or networks and their physical, chemical and biological properties. The topological index of a graph or network is a numeric quantity that characterizes the entire structure of the underlying graph or network. Mathematically, it is a function $T: \Gamma \rightarrow \mathbb{R}$ with the property $T\left(\Omega_{1}\right)=T\left(\Omega_{2}\right)$ if and only if $\Omega_{1}$ and $\Omega_{1}$ are isomorphic graphs, where $\Gamma$ is the collection of all

\footnotetext{
${ }^{*}$ Corresponding author: souravmath94@gmail.com
} 
simple connected graphs and $\mathbb{R}$ is the set of real numbers. Topological indices can be evaluated by their usual definitions, which are time consuming, while a number of indices of a certain category are intended to be derived. A number of algebraic polynomials have been implemented to overcome this laborious strategy. For instance, in the area of distance based indices, Hosoya polynomial plays a remarkable role. By setting the variable value 1 in the first derivative of this polynomial, one can easily obtain the Wiener index, which is the first topological index introduced by Wiener ${ }^{1}$ in 1947 to predict the boiling point of paraffin. There are many such tools like Schultz polynomial, ${ }^{2}$ PI Polynomial, ${ }^{3}$ Clar covering polynomial, ${ }^{4}$ Tutte polynomial $^{5}$ and theta polynomial ${ }^{6}$ etc. Deutsch and Klavzar made significant contribution in the field of degree based topological indices regarding those tools. In 2015, they presented the Mpolynomial $^{7}$ to produce a large number of topological indices. For study on M-polynomial and its applications, readers are referred to. ${ }^{8-12}$ In the last few years, the number of proposed topological indices is rapidly growing due to their chemical significance. Currently, researchers put their attention on the indices based on neighborhood degree sum of nodes. ${ }^{13-19}$ To make the computation of these types of indices easier, the present authors introduced a polynomial named as neighborhood M-polynomial ${ }^{20}$ whose role for neighborhood degree sum based indices is parallel to the role of the M-polynomial for degree based indices. Thus from the neighborhood $\mathrm{M}$ polynomial of a given family of graphs, its neighborhood degree sum based indices can be recovered. Sometimes the function defining a topological index does not allow the neighborhood M-polynomial to obtain topological indices. In that case, equation (2) can be used to get the closed form of the neighborhood degree sum based topological index.

The neighborhood M-polynomial of a graph $\Omega$ is defined as,

$$
N M(\Omega ; x, y)=\Sigma_{\alpha \varsigma \beta} X_{(\alpha, \beta)} x^{\alpha} y^{\beta} .
$$

where $\chi_{(\alpha, \beta)}$ is the total count of edges $u v \in E(G)$ such that $\left\{\tau_{u}, \tau_{v}\right\}=\{\alpha, \beta\}$. We use $N M(\Omega)$ for $N M(\Omega ; x, y)$ in this article. Neighborhood degree sum based topological indices defined on edge set of a graph $\Omega$ can be expressed as:

$$
T(\Omega)=\sum_{w \in E(G)} f\left(\tau_{u}, \tau_{v}\right)
$$

where $f\left(\tau_{w}, \tau_{v}\right)$ is the function of $\tau_{u}, \tau_{v}$ used in the definition of neighborhood degree based indices. The above result can also be written as

$$
T(\Omega)=\Sigma_{\alpha \varsigma \beta} \chi_{(\alpha, \beta)} f(\alpha, \beta) .
$$

Now we describe some neighborhood degree based topological indices.

The third version of Zagreb index ${ }^{16}$ is defined as,

$$
M_{1}^{f}(\Omega)=\Sigma_{w v \in E(\Omega)}\left(\tau_{u}+\tau_{v}\right) .
$$

The neighborhood second Zagreb index ${ }^{19}$ is defined as,

$$
M_{2}^{*}(\Omega)=\Sigma_{w v \in E(\Omega)} \tau_{u} \tau_{v} .
$$

The neighborhood forgotten topological index ${ }^{19}$ is defined as,

$$
F_{N}^{*}(\Omega)=\Sigma_{w v \in E(\Omega)}\left(\tau_{u}{ }^{2}+\tau_{v}{ }^{2}\right) .
$$

The neighborhood second modified Zagreb index ${ }^{20,21}$ is defined as,

$$
M_{2}^{n m}(\Omega)=\sum_{w v \in E(\Omega)} \frac{1}{\tau_{w} \tau_{i}}
$$

The neighborhood general Randić c $^{20,21}$ index is defined as,

$$
N R_{\alpha}(\Omega)=\sum_{w v \in E(\Omega)}\left(\tau_{u} \tau_{v}\right)^{\alpha} .
$$

The third NDe index ${ }^{15}$ is defined as,

$$
N D_{3}(\Omega)=\Sigma_{u v \in E(\Omega)} \tau_{u} \tau_{v}\left(\tau_{u}+\tau_{v}\right) .
$$

The fifth NDe index ${ }^{15}$ is defined as,

$$
N D_{5}(\Omega)=\sum_{w v E(\Omega)}\left[\frac{\tau_{w}}{\tau_{v}}+\frac{\tau_{v}}{\tau_{w}}\right] .
$$

The neighborhood Harmonic index ${ }^{20,21}$ is defined as,

$$
N H(\Omega)=\sum_{w \in E(\Omega)} \frac{2}{\tau_{u}+\tau_{v}}
$$

The neighborhood inverse sum index $x^{20,21}$ is given by

$$
N I(\Omega)=\sum_{u v \in E(\Omega)} \frac{\tau_{u} \tau_{v}}{\tau_{u}+\tau_{v}}
$$

The Sanskruti index ${ }^{13}$ is defined as,

$$
S_{I}(\Omega)=\sum_{w v \in E(\Omega)}\left(\frac{\tau_{u} \tau_{v}}{\tau_{u}+\tau_{v}-2}\right)^{3} .
$$

The relations of some neighborhood degreebased topological indices with the NM-polynomial are shown in the Table 1. 
Table 1

Derivation of some neighborhood degree based topological indices

\begin{tabular}{|c|c|}
\hline Topological index & Derivation from $N M(\Omega)$ \\
\hline$M_{1}^{*}(\Omega)$ & $\left.\left(D_{x}+D_{y}\right)(N M(\Omega))\right|_{x=y=1}$ \\
\hline$M_{2}^{*}(\Omega)$ & $\left.\left(D_{x} D_{y}\right)(N M(\Omega))\right|_{x=y=1}$ \\
\hline$F_{N}^{*}(\Omega)$ & $\left.\left(D_{x}^{2}+D_{y}^{2}\right)(N M(\Omega))\right|_{x=y=1}$ \\
\hline$M_{2}^{n m}(\Omega)$ & $\left.\left(S_{x} S_{y}\right)(N M(\Omega))\right|_{x=y=1}$ \\
\hline$N R_{c \varepsilon}(\Omega)$ & $\left.\left(D_{x x}{ }^{\varepsilon} D_{y}{ }^{\alpha}\right)(N M(\Omega))\right|_{x=y=1}$ \\
\hline$N D_{3}(\Omega)$ & $\left.D_{x} D_{y}\left(D_{x}+D_{y}\right)(N M(\Omega))\right|_{x=y=1}$ \\
\hline$N D_{5}(\Omega)$ & $\left.\left(D_{x} S_{y}+S_{x} D_{y}\right)(N M(\Omega))\right|_{x=y=1}$ \\
\hline$N H(\Omega)$ & $\left.2 S_{x} J(N M(\Omega))\right|_{x=y=1}$ \\
\hline$N I(\Omega)$ & $\left.S_{x} J D_{x} D_{y}(N M(\Omega))\right|_{x=y=1}$ \\
\hline$s_{l}(\Omega)$ & $\left.S_{x}^{3} Q_{-2} J D_{x}{ }^{3} D_{y}{ }^{3}(N M(\Omega))\right|_{x=y=1}$ \\
\hline
\end{tabular}

where,

$$
\begin{gathered}
D_{x}(f(x, y))=x \frac{\partial(f(x, y))}{\partial x}, \\
D_{y}(f(x, y))=y \frac{\partial(f(x, y))}{\partial y}, S_{x}(f(x, y))= \\
\int_{0}^{x} \frac{f(t, y)}{t} d t \\
S_{y}(f(x, y))=\int_{0}^{y} \frac{f(x, t)}{t} d t, f(f(x, y))=f(x, x), Q_{\alpha}(f(x, y))=x^{\alpha} f(x, y) .
\end{gathered}
$$

In recent decades, the advent of networking especially on computers, electrical and biological networks has made it easier to transfer information and essential products in a limited time and with reasonable precision. The rapid development of interconnected circuits has made it possible to create highly integrated networks. Examples of such network include social network, computer network, biological network, World Wide Web, ecological network, neural network etc. The present work deals with the neural network. A neural network model is constructed by a large amount of simple processing neuron nodes organized into a sequence of layers. Javaid and $\mathrm{CaO}^{22}$ studied first time the topological properties of the probabilistic neural network in terms of some degree-based indices in 2017. Then in 2018, Liu et $a .^{23}$ computed some degree-based and distance-based indices of 3-layered probabilistic neural network. Javaid et al. ${ }^{24}$ investigated the topological indices of 4-layered probabilistic neural network in 2019. Some degree based indices of cellular neural network is studied by Imran et al. ${ }^{25}$ in 2019. The present authors derived some degree based and neighborhood degree sum based indices of chemical structures applied for the treatment of COVID-19 using M-polynomial and
NM-polynomial approach $^{26}$. In, $^{27}$ the general Zagreb index of neural network is obtained. Javaid et al. $^{28}$ evaluated degree-based indices of neural network using M-polynomial approach. The goal of the present work is to investigate the usefulness of the aforesaid indices and to compute the NM-polynomials of 3-layered and 4-layered probabilistic neural networks. Then using the expressions of NM-polynomials, we derive some neighbourhood degree sum based indices of aforesaid networks.

The rest of the work is organized as follows. Section 2 contains the materials and methods required to obtain the outcomes. In section 3, the applications and motivations of the work are described. Section 4 contains the computational results for the 3-layered probabilistic neural network. In section 5, the computational aspect of 4-layered probabilistic neural network is described. The work is concluded in section 6 .

\section{MATERIALS AND METHODS}

The present work deals with the investigation of usefulness of some neighborhood degree sum based indices and computation of the indices for 3- 
layered and 4-layered probabilistic neural networks. To check the usefulness of the indices, octane isomer and alkanes (from butane to 2,3,3,4tetramethyl pentane) datasets are considered. The experimental data of different physico-chemical properties for octanes are taken from www.moleculardescriptors.eu/dataset/dataset.htm. the datas related to the alkanes are collected from lcite $\{$ hosa 17$\}$. The indices for the probabilistic neural networks are computed using NMpolynomial. We use some calculus operators to recover the indices from NM-polynomial. Also we use the combinatorial computation, graph theoretical tools, and edge partition methods to get the outcomes. The results are illustrated graphically using MATLAB 2017 and Maple 2015.

\section{APPLICATIONS}

The journey of topological indices was started through the Wiener index ${ }^{1}$ in 1947, where the boiling points of the paraffins were modelled. After that a large number of indices have been defined in the literature to develop quantitative structure property relationship (QSPR) analysis. QSPR analysis is a powerful investigation for breaking down a molecule into a series of numerical values describing its relevant physicochemical properties and biological activities. Descriptors having the strongest correlation in this study give information about essential functional groups of compounds under consideration. Accordingly, we can regulate pharmacological action or physico-chemical properties of drugs by modifying certain groups in the structure of medications. It is usually very costly to test a compound using a wet lab, but the QSPR study allows that cost to be reduced. QSPR approaches can be used to develop models which can predict properties or activities of several networks. An efficient way of encoding structures with determined topological index is therefore necessary for the construction of accurate models. The indices used for the creation of model can offer a chance to concentrate on particular characteristics that account for the activity or property of interest in the network. The indices described in the Introduction section are firstly appeared in. ${ }^{13-16,19,20}$ The chemical applicability of $M_{1}{ }^{\circ}, M_{2}{ }^{*}, F_{N}{ }^{*}, S, N D_{3}$, and $N D_{5}$ are described in. ${ }^{13-16,19}$ The chemical significance of rest of the indices is investigated in this section. In addition, the indices, modelling ability of which are briefly illustrated in, ${ }^{13-16,19}$ are explored here in details. To check the usefulness of a molecular descriptor, one should correlate the index with a standard dataset. Here we consider the benchmark data set of octane isomers. Remarkably, each index correlates well with at least one physico-chemical properties of octane isomers. The absolute correlation coefficients $(\|r\|)$ of the indices with different physico-chemical properties that includes entropy $(S)$, acentric factor $\left(A F^{\prime}\right)$, standard enthalpy of vaporisation $(D H V A P)$, enthalpy of vaporization $(H V A P)$, and heat capacity at $\mathrm{P}$ constant $(C P)$ such that $\|r\| \geq 0.8$ are reported in Table 2. The wellfitted models for each index are listed in equations (4)-(16). We propose to analyse the following linear regression model:

$$
P=A( \pm E)+B( \pm E) S D
$$

Table 2

Correlation of some indices with different properties for octane isomer.

\begin{tabular}{|c|c|c|c|c|c|}
\hline Indices & $S$ & $A F$ & DHVAP & $H V A P$ & $C P$ \\
\hline${ }^{n m} M_{2}$ & 0.933 & 0.966 & 0.904 & 0.859 & - \\
\hline$M_{1}^{\prime}$ & 0.942 & 0.978 & 0.82 & - & - \\
\hline$M_{2}^{*}$ & 0.948 & 0.985 & 0.812 & - & - \\
\hline $\mathrm{NH}$ & 0.939 & 0.987 & 0.858 & - & - \\
\hline$N I$ & 0.962 & 0.99 & 0.87 & - & - \\
\hline$F_{N}^{*}$ & 0.932 & 0.975 & - & - & - \\
\hline $\mathrm{ND}_{3}$ & 0.939 & 0.976 & - & - & - \\
\hline$S_{I}$ & 0.829 & - & - & - & - \\
\hline $\mathrm{ND}_{5}$ & - & - & - & - & 0.848 \\
\hline
\end{tabular}


where $P_{n}, A_{n} E, B$, and $S D$ are properties, intercept, standard error of coefficients, slope, and structure descriptor respectively.

Some statistical parameters, such as the standard error of the model $\left(S_{e}\right)$, the F-test $(F)$ and the significance $\mathrm{F}\left(S F^{\prime}\right)$, are also reported in each model. Using the equation (3), we have the following linear regression models for different topological indices.

$$
\begin{aligned}
& S=87.7433( \pm 1.7423)+37.3974( \pm 3.592) M_{2}^{m W} \\
& S_{e}=1.67, F=108.3925, S F=1.5635 \times 10^{-8} \\
& A F^{\prime}=0.1923( \pm 0.0099)+0.3037( \pm 0.0203) M_{2}^{M m} \\
& S_{e}=0.0094, F^{\prime}=223.0116, S F^{\prime}=8.1665 \times 10^{-11} \\
& D H V A P=7.6736( \pm 0.1758)+3.0746( \pm 0.3624) M_{2}^{m m} \\
& S_{e}=1.685, F=71.9533, S F=2.5729 \times 10^{-7} \\
& S=137.9677( \pm 2.9102)-0.5337( \pm 0.0473) M_{1}^{r} \\
& S_{e}=1.5568, F=127.1587, S F^{\prime}=5.038 \times 10^{-9} \\
& A F^{\prime}=0.6008( \pm 0.0143)-0.0043( \pm 0.0002) M_{1}^{r} \\
& S_{e}=0.0077, F^{\prime}=346.6988, S F^{\prime}=2.8733 \times 10^{-12} \\
& A F^{\prime}=0.4821( \pm 0.0065)-0.0011\left( \pm 4.6471 \times 10^{-5}\right) M_{2}^{*} \\
& S_{e}=0.0062, F=533.5205, S F=1.0277 \times 10^{-13} \\
& S=123.3574( \pm 1.5446)-0.1316( \pm 0.011) M_{2}^{*} \\
& S_{e}=1.4808, F=142.2154, S F=2.2519 \times 10^{-9} \\
& S=72.5693( \pm 3.0258)+19.2832( \pm 1.7627) \mathrm{NH} \\
& S_{e}=1.5991, F=119.6804, S F=7.7624 \times 10^{-9} \\
& A F^{\prime}=0.0649( \pm 0.0112)+0.1589( \pm 0.0065) N H \\
& S_{e}=0.0059, F=593.182, S F=4.5 \times 10^{-14} \\
& S=143.803( \pm 2.7444)-2.6252( \pm 0.1865) \mathrm{NI} \\
& S_{e}=1.2732, F=198.0411, S F=1.9816 \times 10^{-10} \\
& A F^{\prime}=0.6457( \pm 0.0113)-0.0212( \pm 0.0008) N I \\
& S_{e}=0.0052, F=758.9772, S F^{\prime}=6.5429 \times 10^{-15} \\
& S=121.1672( \pm 1.5871)-0.0527( \pm 0.0051) F_{N}^{*} \\
& S_{e}=1.6921, F=105.171, S F=1.932 \times 10^{-8} \\
& A F^{\prime}=0.4652( \pm 0.0075)-0.0004( \pm 2.4422) F_{N}^{*} \\
& S_{e}=0.008, F=314.2044, S F^{\prime}=6.1004 \times 10^{-12}
\end{aligned}
$$

If we go through the models (4)-(16), several remarks can be drawn. The smaller the $S_{e}$ values, the more confident we are regarding the regression equation. Among all the models, equation (14) has the lowest $S_{e}$ value. The consistency of the model improves as the F-value increases. The models (9), 
(12), and (14) have significant F-values. When the $S F$ value is less than 0.05 , then the model is considered to be statistically reliable. In each case, $S F$ value is far less than 0.05 . For each model, the $\|r\|$ value is greater or equal to 0.9 (Table 2). Infact, for the model (14), it is very closed to 1 . The linear fittings of the indices with different physicochemical properties are depicted in Figures 1-5. The solid circles in the Figures 1-5 represent data points and the blue lines represent the regression line. From Figure 3, it is clear that the data points are well-fitted with the linear model (14). Thus we can state that the model (14) is the best fitted compared to the other models. The correlation of $N D_{5}$ index with different properties for octanes is not satisfactory. But it yields well response for 67 alkanes (from butane to 2,3,3,4-tetramethyl pentane). The absolute correlation coefficient of $N D_{5}$ with boiling points (bp), critical temperature (ct), molar volumes $(\mathrm{mv})$ at $20^{\circ} \mathrm{C}$, molar refractions (mr) at $20^{\circ} \mathrm{C}$, heats of vaporization (hv) at $25^{\circ} \mathrm{C}$ and surface tensions (st) at $20^{\circ} \mathrm{C}$ are reported in Table 3. The comparative correlations of different indices with different properties are depicted in Figure 6 and Figure 7.
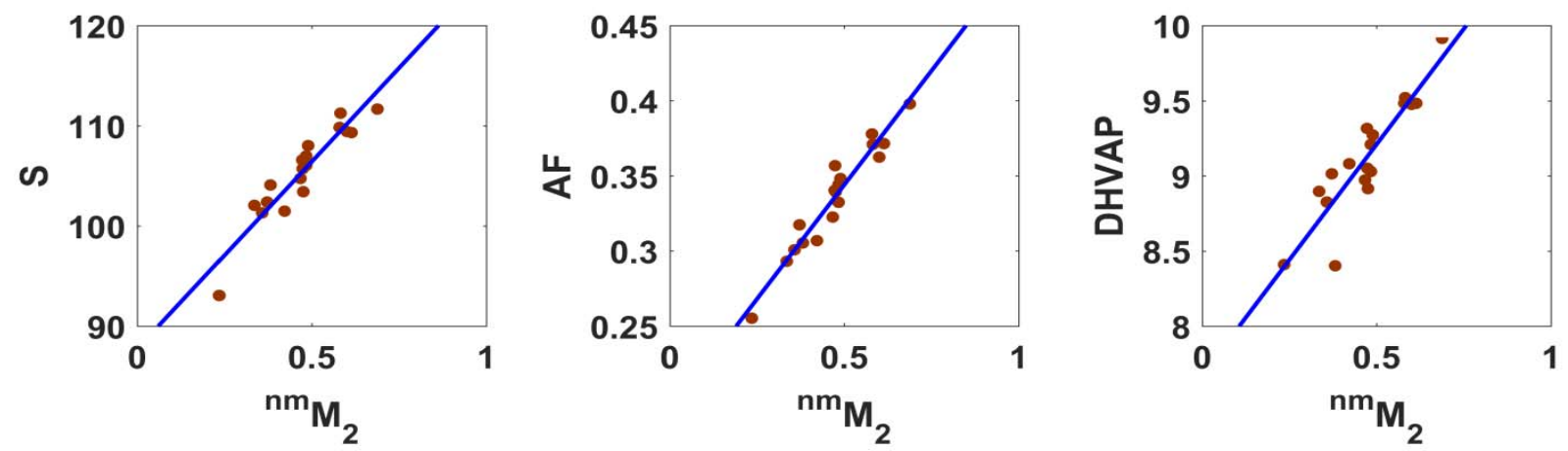

Fig. 1 - Correlation of $M_{2}^{n m}$ with different properties for octanes.
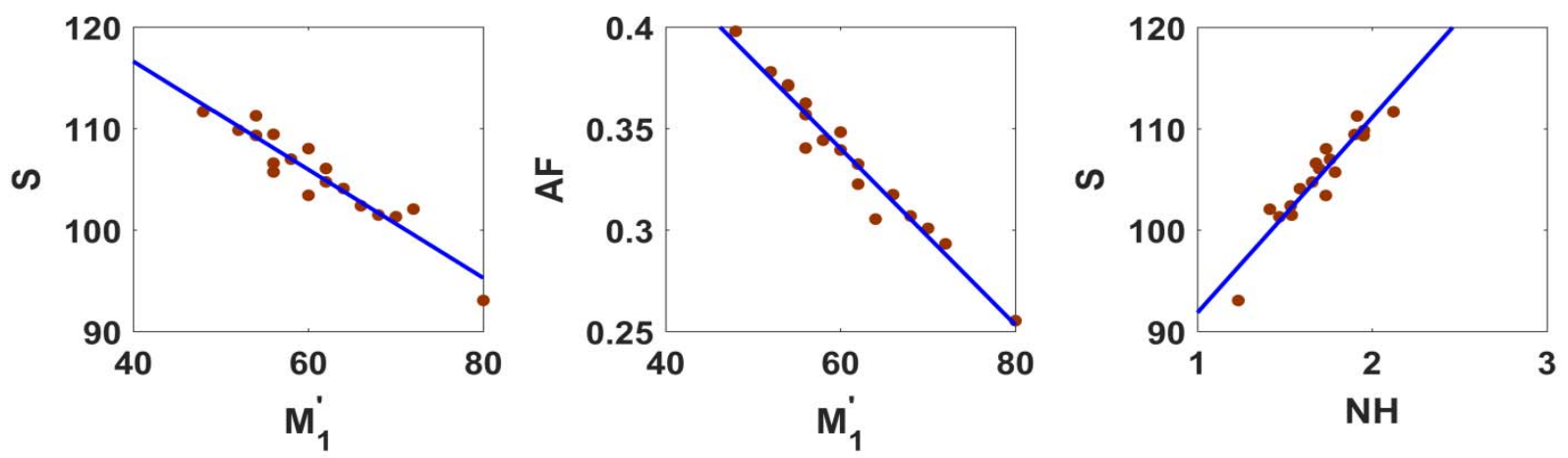

Fig. 2 - Correlation of $M_{1}^{f}$ and $N H$ with different properties for octanes.
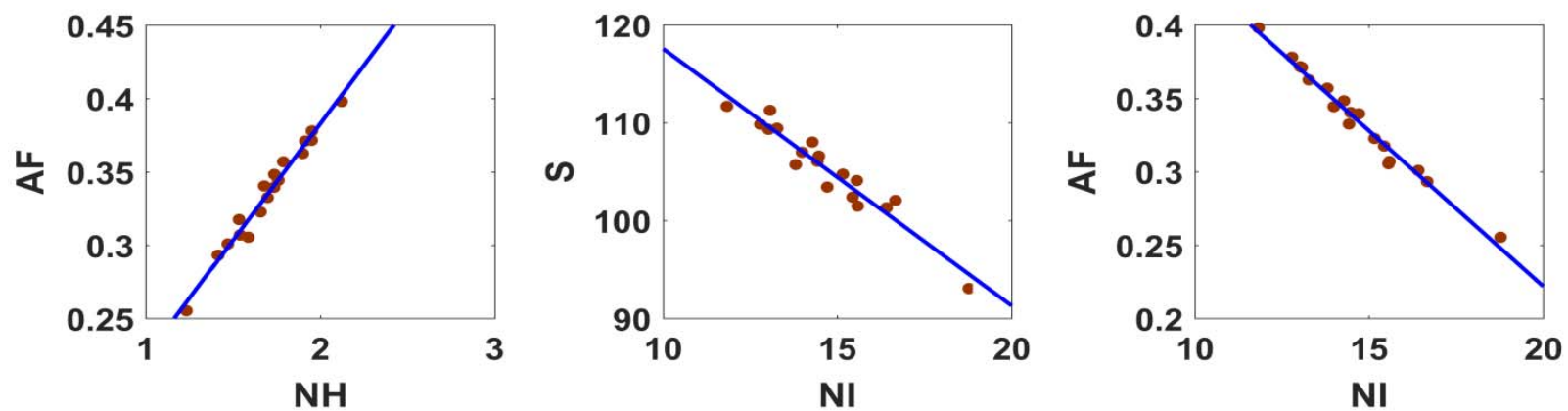

Fig. 3 - Correlation of $N H$ and $N I$ with different properties for octanes. 

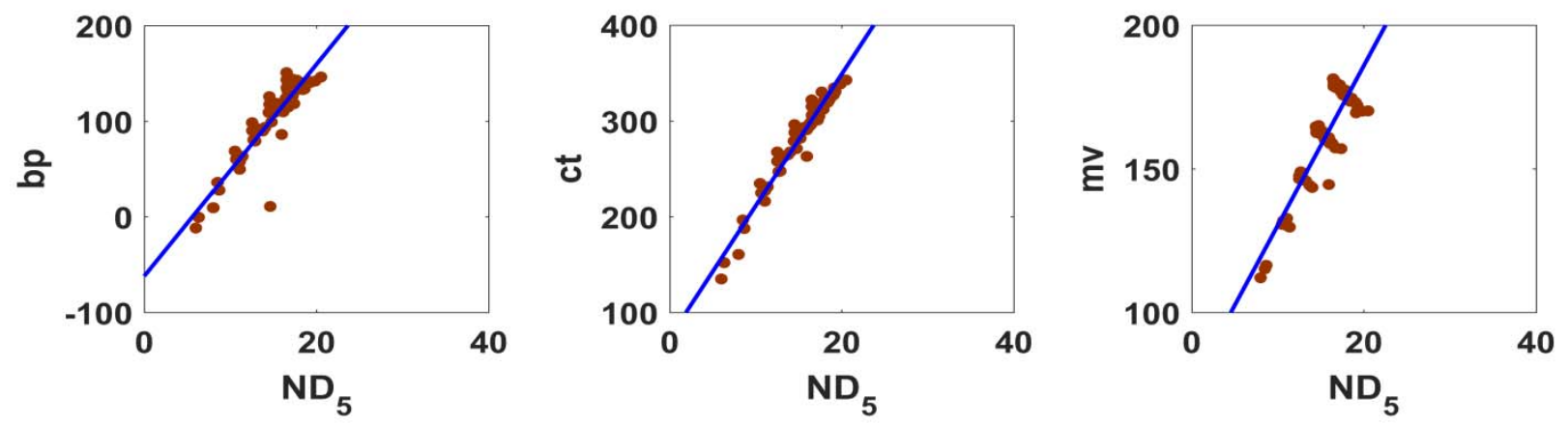

Fig. 4 - Correlation of $N D_{5}$ with different properties for octanes.
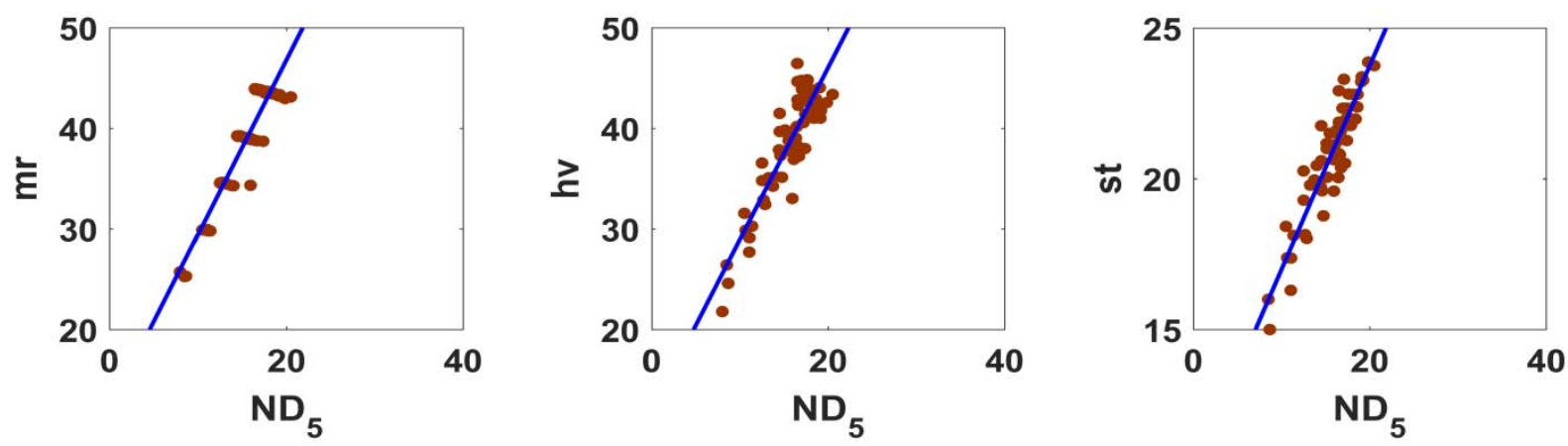

Fig. 5 - Correlation of $\mathrm{ND}_{\mathrm{g}}$ with different properties for octanes.

Table 3

Correlation of $N D_{5}$ with different properties for alkanes

\begin{tabular}{ccccccccc}
\hline \multicolumn{2}{c}{ properties } & & & & & & & \\
Indices & & & $c t$ & $m v$ & $m r$ & $h v$ & $s t$ \\
\hline \multirow{2}{*}{$N D_{5}$} & 0.917 & 0.978 & 0.889 & 0.932 & 0.895 & 0.927
\end{tabular}
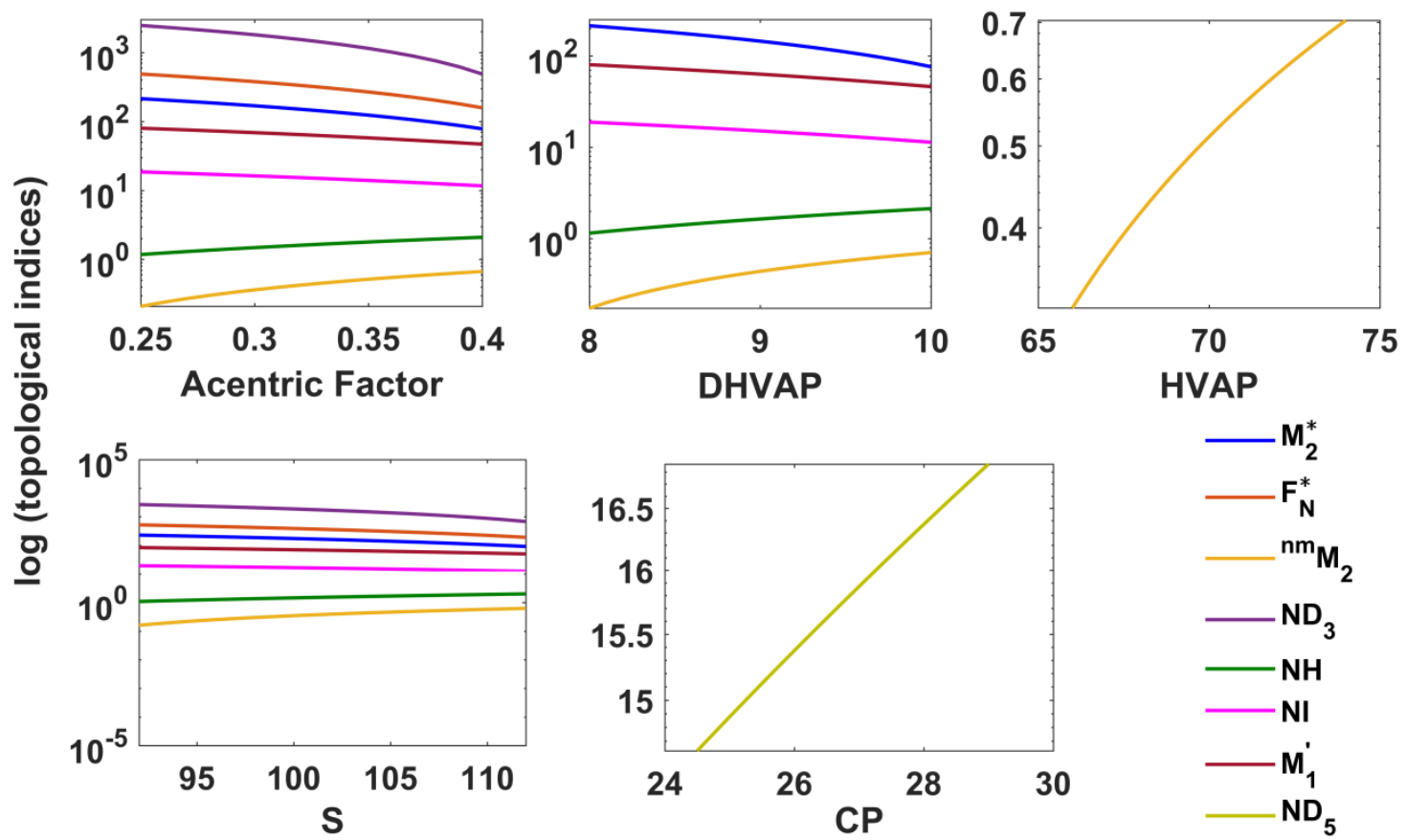

Fig. 6 - Correlation of topological indices with different properties for octane isomers.

To make the plotting clear, logarithm scale is used along the vertical axis. 


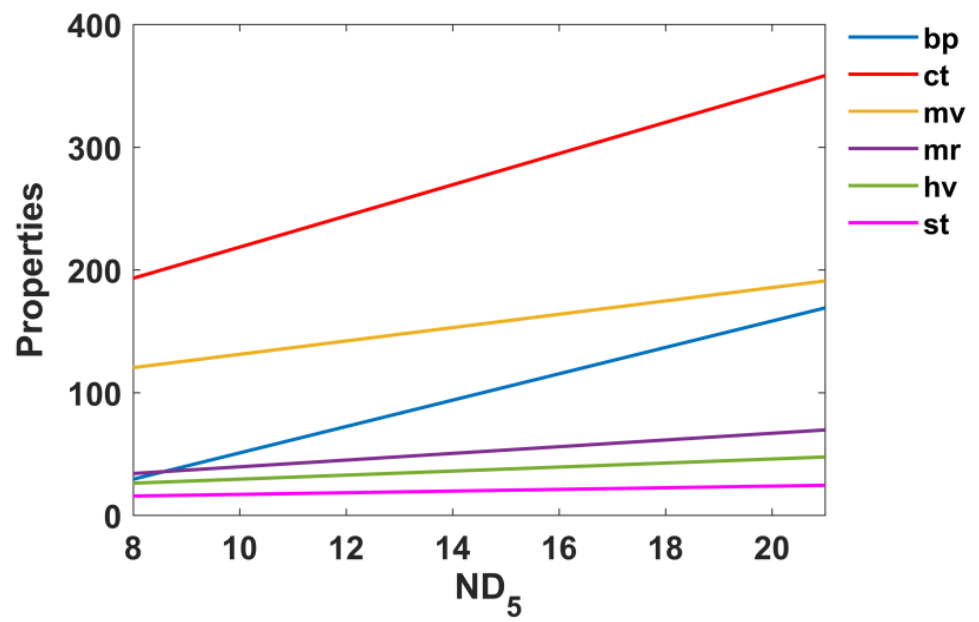

Fig. 7 - Correlation of $N D_{5}$ with different properties for alkanes.

Besides the structure-property/structure-activity modelling, a good descriptor should discriminate isomers. The isomer discrimination ability of an index is measured by sensitivity introduced by Konstantinova ${ }^{30}$ and is defined by:

$$
S_{T}=\frac{N-N_{T}}{N}
$$

where $N$ and $N_{T}$ are the total number of isomers and the count of isomers that cannot be discriminated by the descriptor $T$, respectively. The isomer discrimination ability of an index is directly proportional to $S_{T}$. Clearly, its maximum value is 1 . Therefore, $S_{T}$ plays a major role in the discriminating power of an index. The indices having good discrimination ability captures more structural information. The sensitivity of $M_{2}^{*}, F_{N}^{*}, N D_{3}$, and $N D_{5}$ indices for octane isomers are checked in. ${ }^{15,19}$ They have the $S_{T}$ values $1,0.889,1$, and 1 , respectively. In this article, we calculate that the $S_{T}$ values of $M_{2}^{n m}, N H$, and $N I$ are $0.944,1$, and 1, respectively. These results outperform the well established and most used degree and distance based indices as described in Table 4 in. ${ }^{15}$

\section{COMPUTATIONAL ASPECTS OF A 3-LAYERED PROBABILISTIC NEURAL NETWORK $P N N(N, K, M)$}

The 3-layered probabilistic neural network consists of 3 layers of nodes. The first, second and third layers are known as input, hidden and output layers, respectively. Let, the first, second and third layers contain $n$ nodes, $k$ classes with $m$ nodes in each class and $k$ nodes, respectively. Each node of input layer connected with every node in hidden layer and each node of a class in the hidden layer is connected to a specific node in the output layer. This network is denoted as $P N N(n, k, m)$. The graphical representation of $P N N(n, k, m)$ is shown in Figure 8. We compute the $N M$-polynomial of a 3-layered probabilistic neural network in the following theorem.

Theorem 1. Let $\Omega \cong \operatorname{PNN}(n, k, m)$ be a 3-layered probabilistic neural network. Then we have,

$$
\begin{gathered}
N M(\Omega)=k m n x^{m(k n+1)} y^{k m(n+1)} \\
+k m x^{m(n+1)} y^{m(k n+1)} .
\end{gathered}
$$

Proof. $P N N(n, k, m)$ has $k m(n+1)$ number of edges. Its edge set can be partitioned into two sets $E_{1}$ and $E_{2}$ based on the degree sum of neighbor of end vertices of each edge, where $E_{1}=\left\{u v \in E(\Omega): \tau_{u}=(n k+1) m, \tau_{v}=(n+1) k m\right.$ and

$E_{2}=\left\{u v \in E(\Omega): \tau_{u}=(\mathrm{n}+1) \mathrm{m}, \tau_{v}=(\mathrm{nk}+1) \mathrm{m}\right\}$. Clearly, $\left|E_{1}\right|=n k m,\left|E_{2}\right|=\mathrm{km}$.

The $N M$-polynomial of $\Omega$ can be obtained as follows.

$$
\begin{gathered}
N M(\Omega ; x, y)=\sum_{\alpha \leq \beta} \chi_{(\alpha, \beta)} x^{\alpha} y^{\beta} \\
=\left|E_{1}\right| \mathrm{x}^{\mathrm{m}(\mathrm{kn}+1)} \mathrm{y}^{\mathrm{km}(\mathrm{n}+1)}+\left|E_{2}\right| \mathrm{x}^{\mathrm{m}(\mathrm{n}+1)} \mathrm{y}^{\mathrm{m}(\mathrm{kn}+1)} \\
=\mathrm{kmnn} \mathrm{x}^{\mathrm{m}(\mathrm{kn}+1)} \mathrm{y}^{\mathrm{km}(\mathrm{n}+1)}+\mathrm{km}^{\mathrm{m}(\mathrm{n}+1)} \mathrm{y}^{\mathrm{m}(\mathrm{kn}+1)} .
\end{gathered}
$$

This completes the proof.

Now using this $N M$-polynomial, we calculate some neighborhood degree based topological indices of $P N N(n, k, m)$ in the following theorem. 


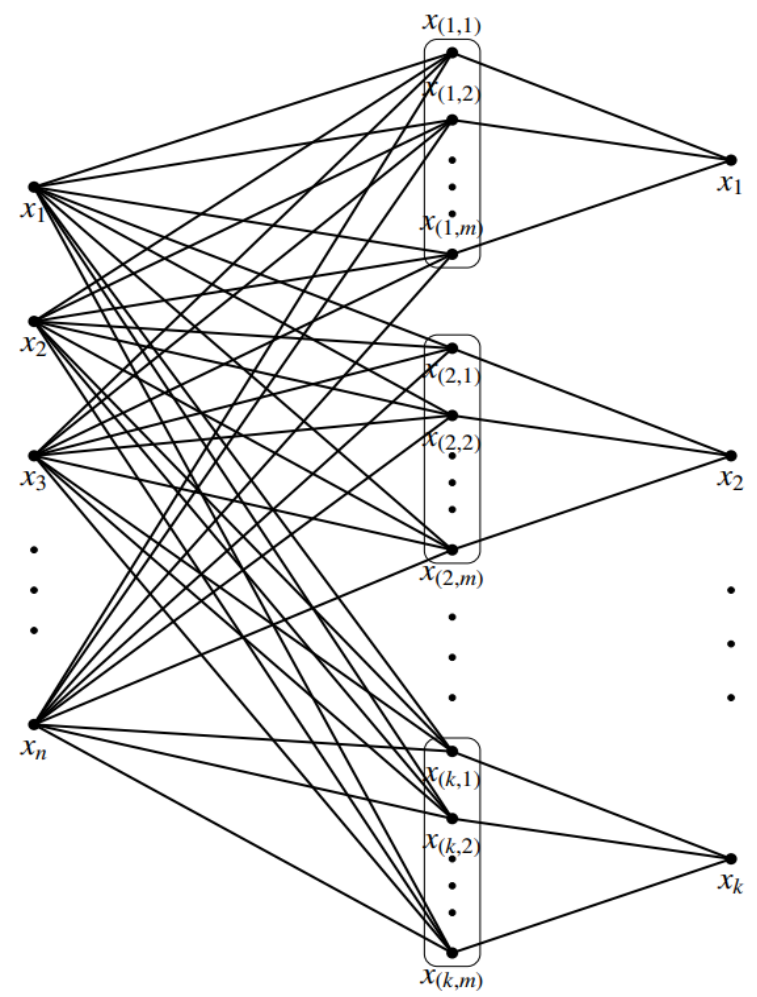

Fig. 8 - The 3-layered probabilistic neural network $P N N(n, k, m)$.

Theorem 2. Let $\Omega$ be a 3-layered probabilistic neural network $\operatorname{PNN}(\mathrm{n}, \mathrm{k}, \mathrm{m})$. Then we have,

$$
M_{1}^{\prime}(\Omega)=2 k m^{2}\left(k n^{2}+k n+n+1\right),
$$

$M_{2}^{*}(\Omega)=k m^{3}(k n+1)\left(k n^{2}+k n+n+\right.$

1)

$$
\begin{gathered}
F_{N}^{*}(\Omega)=k m^{3}\left[2 k^{2} n^{3}+3 k^{2} n^{2}+\right. \\
\left.2 n k^{2}+2 k n^{2}+2 k n+n^{2}+3 n+2\right] \\
M_{2}^{n m}(\Omega)=\frac{k+n}{m(n+1)(k n+1)^{2}}
\end{gathered}
$$

$N R_{\alpha}(\Omega)=n k m\left[k m^{2}(n+1)(n k+\right.$

1) $]^{\alpha}+k m\left[m^{2}(n+1)(k n+1)\right]^{\alpha}$

$$
\begin{aligned}
& N D_{3}(\Omega)=k m^{4}(n+1)(n k+ \\
& \text { 1) }\left(2 k^{2} n^{2}+n k^{2}+2 k n+n+2\right)
\end{aligned}
$$

$$
N D_{5}(\Omega)=\frac{n}{(n+1)(k n+1)}\left(2 k^{2} n^{3}+n^{2} k^{3}+\right.
$$$$
\left.3 n k^{2}+3 k n^{2}+2 k^{2} n^{2}+2 k n+2 k+n\right)
$$

$$
N H(\Omega)=2 \frac{k\left(k n^{2}+2 k n+n^{2}+k+2 n+1\right)}{(2 k n+k+1)(k n+n+2)}
$$

$N I(\Omega)=$

$\underline{k m^{2}(n+1)(k n+1)\left(k^{2} n^{2}+k n^{2}+4 k n+k+1\right)}$ $(2 k n+k+1)(k n+n+2)$

$$
\begin{aligned}
& S_{I}(\Omega)=\frac{n k^{4} m m^{7}(n+1)^{9}(n k+1)^{9}}{\{(2 n k+k+1) m-2\}^{8}}- \\
& \frac{k m^{7}(n+1)^{8}(n k+1)^{8}}{\{(k n+n+2) m-2\}^{8}}
\end{aligned}
$$

Proof. Let $N M(\Omega)=f(x, y)=\mathrm{kmnx}^{\mathrm{m}(\mathrm{kn}+1)} \mathrm{y}^{\mathrm{km}(\mathrm{n}+1)}+$ $+\mathrm{kmx}^{\mathrm{m}(\mathrm{n}+1)} \mathrm{y}^{\mathrm{m}(\mathrm{kn+1})}$.

Then we have

$$
\begin{aligned}
& \left(D_{x}+D_{y}\right)(f(x, y))=\mathrm{kmm}(2 \mathrm{kmm}+\mathrm{km}+\mathrm{m}) \mathrm{x}^{\mathrm{m}(\mathrm{kn}+1)} \mathrm{y}^{\mathrm{km}(\mathrm{n}+1)} \\
& +k m(k m n+m n+2 m) x^{m(n+1)} y^{m(k n+1)}, \\
& \left(D_{x} D_{y}\right)(f(x, y))=\mathrm{nk}^{2} \mathrm{~m}^{3}(\mathrm{nk}+1)(\mathrm{n}+1) \mathrm{x}^{\mathrm{m}(\mathrm{kn}+1)} \mathrm{y}^{\mathrm{km}(\mathrm{n}+1)}+\mathrm{km}^{3}(\mathrm{nk}+1)(\mathrm{n}+1) \mathrm{x}^{\mathrm{m}(\mathrm{n}+1)} \mathrm{y}^{\mathrm{m}(\mathrm{kn}+1)} \text {, } \\
& \left(D_{x}^{2}+D_{y}^{2}\right)(f(x, y))=n m^{3}\left[(n k+1)^{2}+(n k+k)^{2}\right] x^{m(k n+1)} y^{k m(n+1)}+k^{3}\left[(n+1)^{2}+\right. \\
& \left.(\mathrm{nk}+1)^{2}\right] \mathrm{x}^{\mathrm{m}(\mathrm{n}+1)} \mathrm{y}^{\mathrm{m}(\mathrm{kn}+1)} \\
& S_{x} S_{y}(f(x, y))=\frac{n}{m(n+1)(n k+1)} x^{m(k n+1)} y^{k m(n+1)}+\frac{k}{m(n+1)(n k+1)} x^{m(n+1)} y^{m(k n+1)} \text {, } \\
& D_{x}^{\alpha} D_{y}^{\alpha}(f(x, y))=\operatorname{kmn}\left[\mathrm{km}^{2}(\mathrm{n}+1)(\mathrm{nk}+1)\right]^{\alpha} \mathrm{x}^{\mathrm{m}(\mathrm{kn}+1)} \mathrm{y}^{\mathrm{km}(\mathrm{n}+1)}+ \\
& \operatorname{km}\left[m^{2}(n+1)(n k+1)\right]^{\alpha} x^{m(n+1)} y^{m(k n+1)}, \\
& D_{x} D_{y}\left(D_{x}+D_{y}\right)(f(x, y))=\mathrm{nk}^{2} \mathrm{~m}^{3}\{(\mathrm{n}+1)(\mathrm{nk}+1)(2 \mathrm{nkm}+\mathrm{km}+\mathrm{m})\} \mathrm{x}^{\mathrm{m}(\mathrm{kn}+1)} \mathrm{y}^{\mathrm{km}(\mathrm{n}+1)}+ \\
& k m^{3}\{(n+1)(n k+1)(n k m+m m+2 m)\} x^{m(n+1)} y^{m(k n+1)}, \\
& \left(D_{x} S_{y}+S_{x} D_{y}\right)(f(x, y))=\operatorname{kmn}\left[\frac{(\mathrm{nk}+1)}{(\mathrm{n}+1) \mathrm{k}}+\frac{(\mathrm{n}+1) \mathrm{k}}{(\mathrm{nk}+1)}\right] \mathrm{x}^{\mathrm{m}(\mathrm{kn}+1)} \mathrm{y}^{\mathrm{km}(\mathrm{n}+1)}+ \\
& \operatorname{km}\left[\frac{(\mathrm{n}+1)}{(\mathrm{nk}+1)}+\frac{(\mathrm{nk}+1)}{(\mathrm{n}+1)}\right] \mathrm{x}^{\mathrm{m}(\mathrm{n}+1)} \mathrm{y}^{\mathrm{m}(\mathrm{kn}+1)} \text {, }
\end{aligned}
$$




$$
\begin{gathered}
S_{x} J(f(x, y))=\frac{n k}{2 n k+k+1} x^{m(2 k n+k+1)}+\frac{k}{n k+n+2} x^{m(k n+n+2)}, \\
S_{x} f D_{x} D_{y}(f(x, y))=\frac{\mathrm{mk}^{2} m^{2}(n+1)(n k+1)}{2 n k+k+1} x^{m(2 k n+k+1)}+\frac{k^{2}}{n k+n+2} x^{m(k n+n+2)}, \\
S_{x}^{3} Q_{-2} J D_{x}^{3} D_{y}^{3}(f(x, y))=\frac{n k^{4} m^{7}(n+1)^{8}(n k+1)^{8}}{\{(2 n k+k+1) m-2\}^{8}} x^{m(2 k n+k+1)-2}+\frac{k m^{7}(n+1)^{8}(n k+1)^{8}}{\{(n k+n+2) m-2\}^{8}} x^{m(k n+n+2)-2} .
\end{gathered}
$$

Using Table 1, we can easily obtain the required result.
The surfaces related to the topological indices of $P N N(n, k, 2)$ are plotted in Figure 9, Figure 10 and Figure 11.

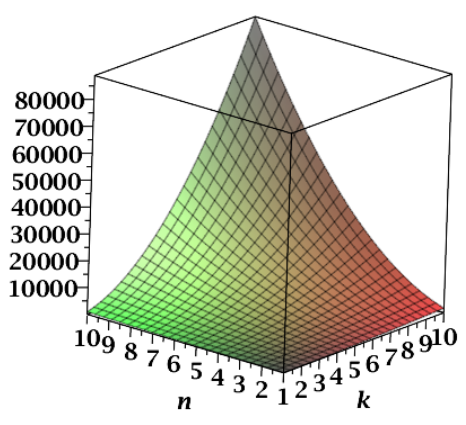

(a)

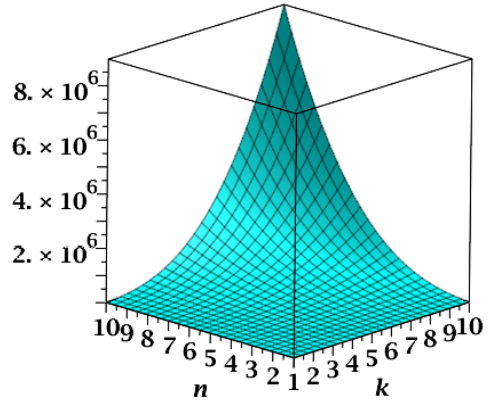

(b)

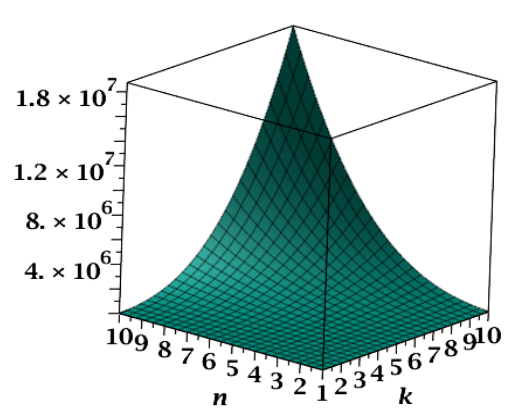

(c)

Fig. 9 - (a) $M_{1}^{f}$ (b) $M_{2}^{*}$ and (c) $F_{N}^{*}$ index of $P N N(n, k, 2)$.

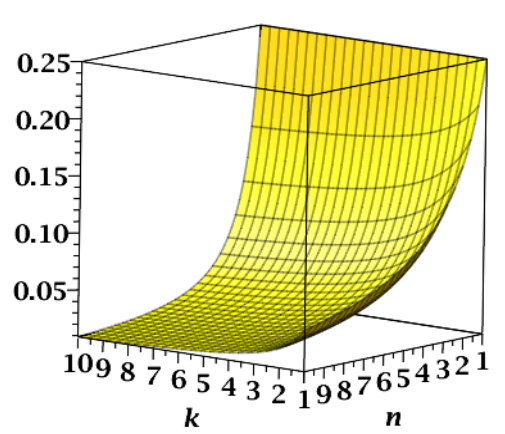

(a)


(c) (b)

Fig. $10-$ (a) $M_{2}^{n m}$ (b) $N D_{3}$ and (c) $N D_{5}$ index of $P N N(n, k, 2)$.

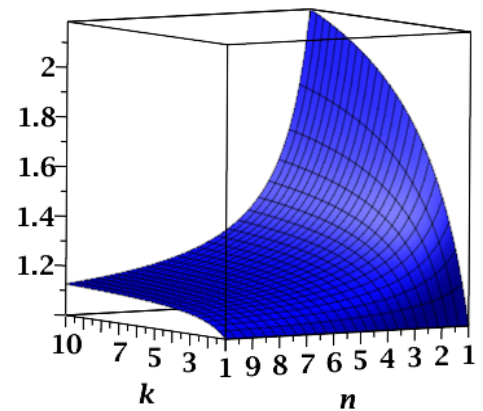

(a)
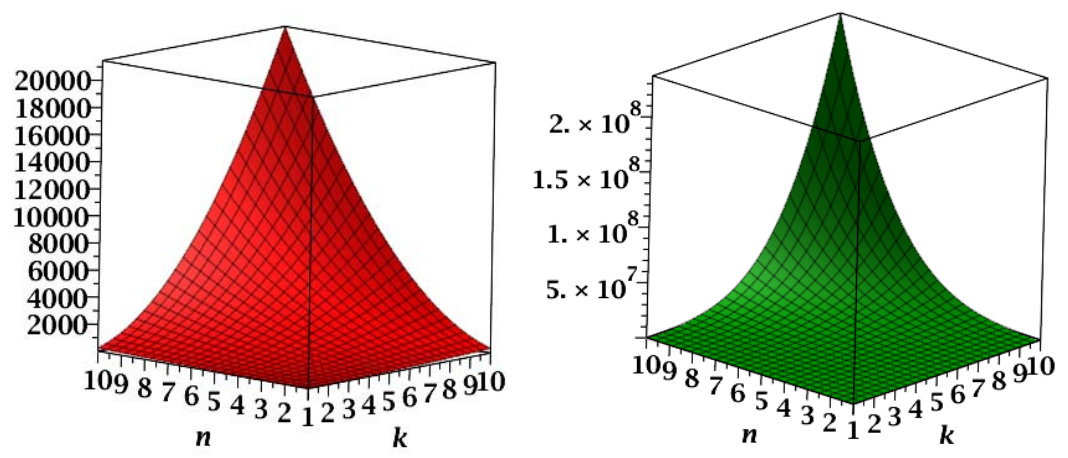

(c)

Fig. 11 - (a) $N H$ (b) $N I$ and (c) $S_{I}$ index of $P N N(n, k, 2)$. 


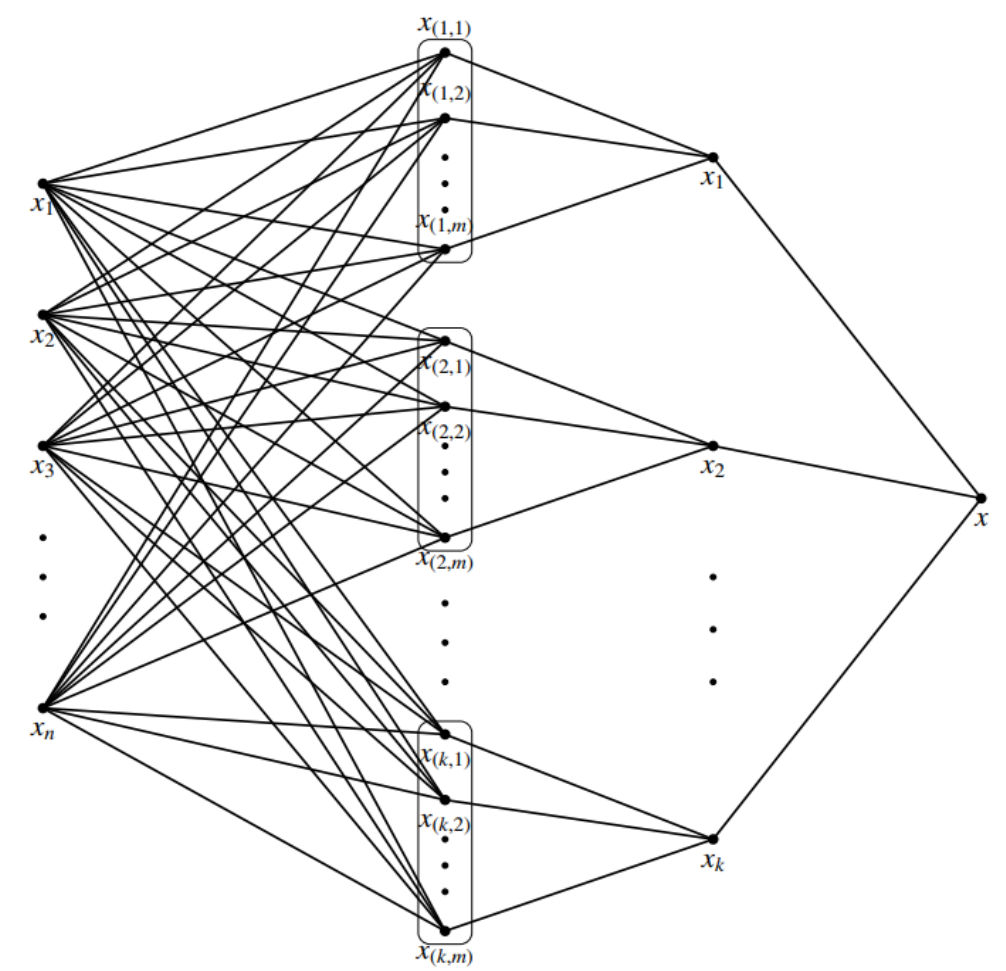

Fig. 12 - The 4-layered probabilistic neural network $P N N(n, k, m, 1)$.

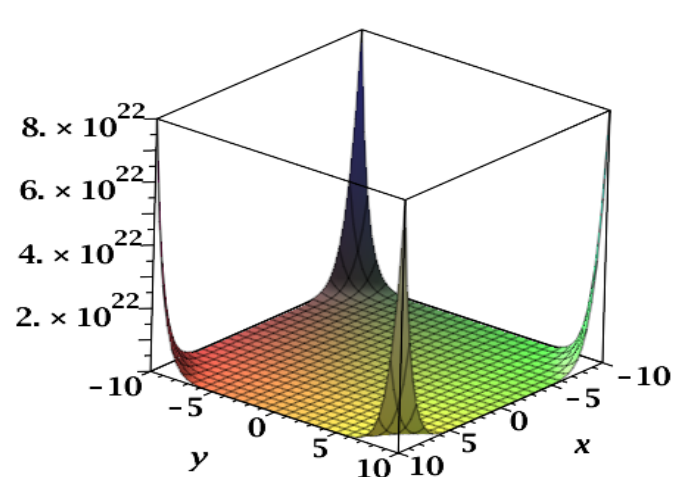

(a)

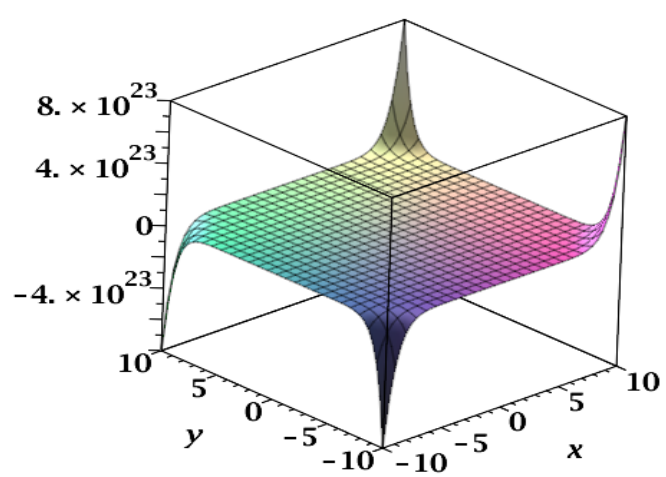

(b)

Fig. 13 - The $N M$-polynomal of (a) $P N N[2,2,2]$ and (b) $P N N[2,2,2,1]$.

\section{COMPUTATIONAL ASPECTS OF A 4-LAYERED PROBABILISTIC NEURAL NETWORK $P N N(N, K, M, 1)$}

The 4-layered probabilistic neural network consists of 4 layers of nodes. The first, second, third and fourth layers are known as input, hidden, summation and output layers, respectively. Let, the first, second, third and fourth layers contain $n$ nodes, $k$ classes with $m$ nodes in each class, $k$ nodes and 1 node, respectively. Each node of input layer connected with every node in hidden layer, each node of a class in the hidden layer is connected to a specific node in the summation layer and all the nodes of summation layer are connected to the only node of output layer. We denote this network as $\operatorname{PNN}(n, k, m, 1)$. The graphical representation of $\operatorname{PNN}(n, k, m, 1)$ is shown in Figure 12. We compute the NMpolynomial of a 4-layered probabilistic neural network PNN $(n, k, m, 1)$ in the following theorem.

Theorem 3. Let $\Omega$ be a 4-layered probabilistic neural network $\operatorname{PNN}(\mathrm{n}, \mathrm{k}, \mathrm{m}, 1)$. Then we have, $N M(\Omega)=k m n x^{k m n+m+1} y^{k m(n+1)}+$ $k m x^{m(n+1)+k} y^{k m n+m+1}+k x^{k(m+1)} y^{m(n+1)+k}$. 
Proof. The 4-layered probabilistic neural network $P N N(n, k, m, 1)$ has $k m n+k m+k$ number of edges. Its edge set can be partitioned into three sets $E_{1}, E_{2}$, and $E_{3}$ based on the degree sum of neighbors of end vertices of each edge, where

$$
\begin{aligned}
& E_{1}=\left\{u v \in E(\Omega): \tau_{u}=k m(n+1), \tau_{v}=k m n+\right. \\
& m+1\} \\
& \quad E_{2}=\left\{u v \in E(\Omega): \tau_{u}=k m+m+1, \tau_{v}=\right. \\
& \quad m(n+1)+k\} \\
& \text { and } E_{3}=\{u v \in E(\Omega):
\end{aligned}
$$

$\left.\tau_{u}=m(n+1)+k, \tau_{v}=k(m+1)\right\} . \quad$ Clearly $\left|E_{1}\right|=m m,\left|E_{2}\right|=k m$, and $\left|E_{3}\right|=k$. The $N M$ -

$$
\begin{aligned}
& N M(\Omega ; x, y)=\sum_{\alpha \leq \beta} x_{(\alpha, \beta)} x^{\alpha} y^{\beta} \\
& M_{1}^{\prime}(\Omega)=2 k^{2} m^{2} n^{2}+2 n k^{2} m^{2}+2 k n m^{2}+2 k m^{2}+2 m k^{2}+2 k m m+2 k m+2 k^{2}, \\
& M_{2}^{*}(\Omega)=k^{3} m^{3} n^{3}+2 k^{2} n^{2} m^{3}+k^{2} m^{2} n^{2}+n^{2} k^{3} m^{3}+2 n k^{2} m^{3}+m m^{2} k^{3}+2 n k^{2} m^{2}+k n m^{3}+ \\
& m m k^{2}+k m^{3}+2 k^{2} m^{2}+m k^{3}+m k^{2}+k^{3} \\
& F_{N}^{*}(\Omega)=2 k^{3} m^{3} n^{3}+3 n^{2} k^{3} m^{3}+n k^{3} m^{3}+3 k n m^{3}+2 k^{2} n^{2} m^{3}+2 k^{2} m^{2} n^{2}+2 n k^{2} m^{3}+ \\
& 4 k m m^{2}+4 k m m^{2}+4 n k^{2} m^{2}+k n^{2} m^{3}+k m^{2} n^{2}+2 m n k^{2}+k m n+2 k m^{3}+3 m k^{3}+2 k^{2} m^{2}+ \\
& k^{3} m^{2}+3 k m^{2}+2 m k^{2}+k m+2 k^{3} \\
& M_{2}^{n m}(\Omega)=\frac{n}{(n+1)(k m n+m+1)}+\frac{k m}{(k m n+m+1)(m n+m+k)}+\frac{1}{(m+1)(m n+m+k)} \\
& N R_{\alpha}(\Omega)=n k m[\mathrm{~km}(\mathrm{n}+1)(\mathrm{km}+\mathrm{m}+1)]^{\alpha}+k[(\mathrm{~km}+\mathrm{m}+1)(\mathrm{mm}+\mathrm{m}+\mathrm{k})]^{\alpha}+ \\
& k[\mathrm{k}(\mathrm{m}+1)(\mathrm{mm}+\mathrm{m}+\mathrm{k})]^{\alpha} \\
& N D_{3}(\Omega)=2 k^{4} m^{4} n^{4}+n^{3} k^{4} m^{4}+n^{2} k^{4} m^{4}+4 k^{3} n^{3} m^{4}+3 k^{3} m^{3} n^{3}+5 n^{2} k^{3} m^{4}+n^{2} m^{3} k^{4}+ \\
& 6 n^{2} k^{3} m^{3}+k^{2} n^{3} m^{4}+5 k^{2} n^{2} m^{4}+5 k^{2} n^{2} m^{3}+4 k^{2} m^{4} n+6 k^{3} m^{3} n+m m^{2} k^{4}+8 n k^{2} m^{3}+ \\
& 2 k n^{2} m^{3}+3 k n m^{4}+4 k n m^{3}+5 n m^{2} k^{3}+3 n k^{2} m^{2}+k n m^{2}+2 k m^{4}+4 k^{2} m^{3}+5 m^{2} k^{3}+ \\
& 3 k m^{3}+4 k^{2} m^{2}+4 m k^{3}+k m^{2}+k^{2} m+2 k^{2} m^{2} n^{2}+k^{3} m^{3}+k^{4} m^{2}+2 m k^{4}+3 m n k^{3}+ \\
& m k^{4}+k^{2} m^{2}+2 k^{4} \text {, }
\end{aligned}
$$

$$
\begin{gathered}
N D_{5}(\Omega)=k m n\left[\frac{k m(n+1)}{k m n+m+1}+\frac{k m n+m+1}{k m(n+1)}\right]+k m\left[\frac{k m n+m+1}{m n+m+k}+\frac{m n+m+k}{k m n+m+1}\right]+k\left[\frac{m n+m+k}{k(m+1)}+\frac{k(m+1)}{m n+m+k}\right] \\
N H(\Omega)=2\left[\frac{k m n}{2 k m n+k m+m+1}+\frac{k m}{k m n+m n+2 m+k+1}+\frac{k}{k m+m n+2 k+m}\right. \\
N I(\Omega)=\frac{n k^{2} m^{2}(n+1)(k m n+m+1)}{2 k m n+k m+m+1}+\frac{k m(k m n+m+1)(m n+m+k)}{k m n+m n+2 m+k+1}+\frac{k^{2}(m+1)(m n+m+k)}{k m+m n+2 k+m}, \\
S_{F}(\Omega)=\frac{k m n[k m(n+1)(k m n+m+1)]^{3}}{(2 k m n+k m+m-1)^{5}}+\frac{k[(k m n+m+1)(m n+m+k)]^{3}}{(k m n+m n+2 m+k-1)^{3}}+\frac{k[k(m+1) j m n+m+k)]^{3}}{(k m+m n+2 k+m-2)^{2}} .
\end{gathered}
$$

This completes the proof. of the parameters are depicted in Figure 13. indices of the 4-layered probabilistic neural network $\operatorname{PNN}(n, k, m, 1)$ like theorem 2 in the

Theorem 4. Let $\Omega$ be a 4-layered probabilistic 


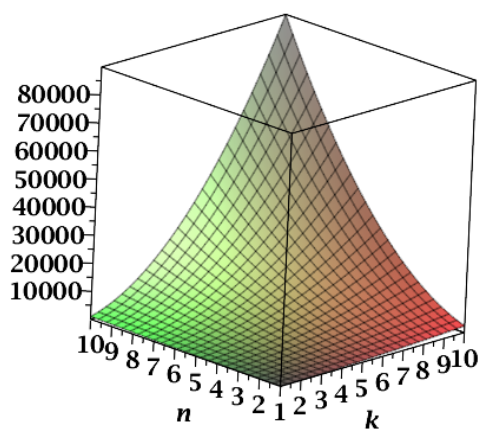

(a)

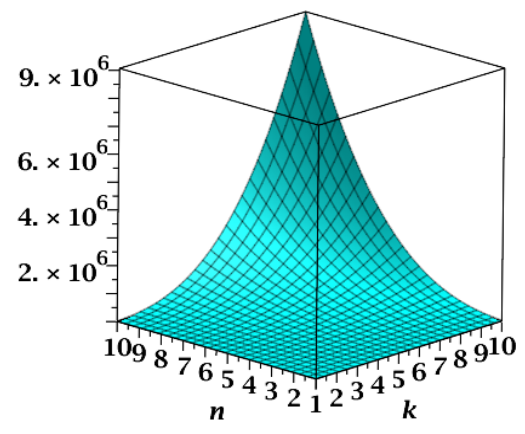

(b)

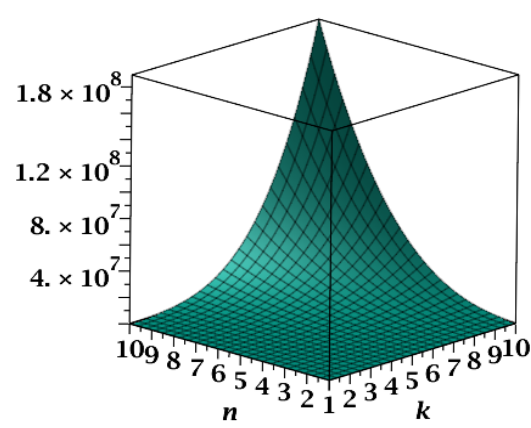

(c)

Fig. $14-$ (a) $M_{1}^{k}$ (b) $M_{2}^{*}$ and (c) $F_{N}^{*}$ index of $P N N(n, k, 2,1)$.

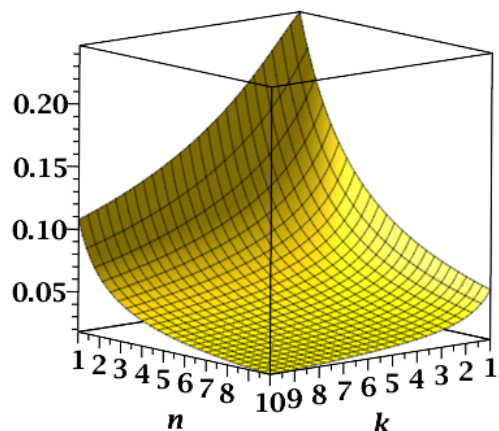

a)

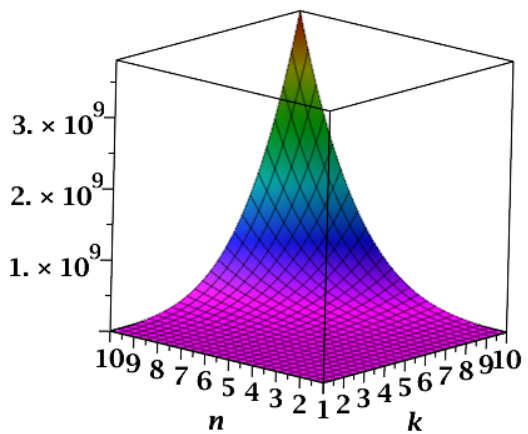

(b)

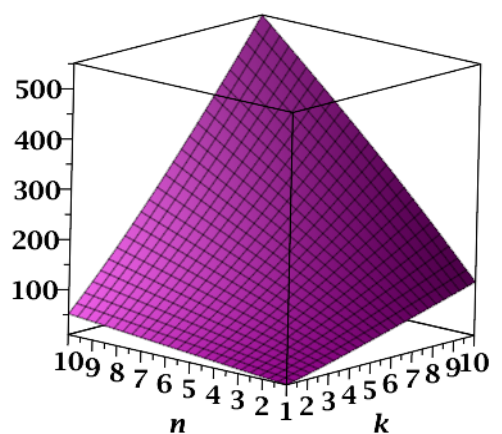

(c)

Fig. $15-$ (a) $M_{2}^{n m m}$ (b) $N D_{3}$ and (c) $N D_{5}$ index of $P N N(n, k, 2,1)$.

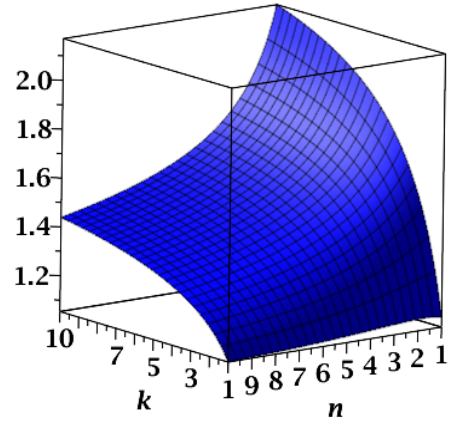

(a)

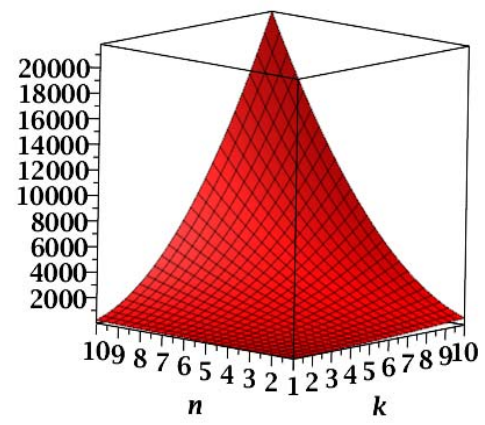

(b)

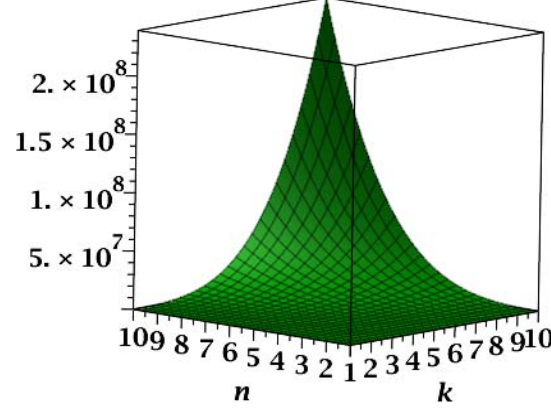

(c)

Fig. 16 - (a) $N H$ (b) $N I$ and (c) $S_{I}$ index of $P N N(n, k, 2,1)$.

The surfaces related to the topological indices of $\operatorname{PNN}(n, k, 2,1)$ are plotted in Figure 14, Figure 15 and Figure 16.

\section{CONCLUSIONS}

In this paper, we obtained some neighborhood degree sum based indices for two types of probabilistic neural networks using neighborhood M-polynomial. Firstly, the general form of NMpolynomial for the 3-layered and 4-layered probabilistic neural networks are computed and then using those expressions, some neighborhood degree sum based indices are recovered. The usefulness of the indices is also established here. From the discussion in section 3 , we can conclude that the response of $N I$ in modelling physico- 
chemical properties of octanes is the best among all the indices under consideration. To visualize the results, their graphical representations have been made. The results can be helpful to understand the topologies of the aforesaid networks.

Acknowledgements. The first author is very obliged to the Department of Science and Technology (DST), Government of India for the Inspire Fellowship [IF170148].

\section{REFERENCES}

1. H. Wiener, J. Am. Chem. Soc., 1947, 69, 17-20.

2. F. Hassani, A. Iranmanesh and S. Mirzaie, MATCH Commun. Math. Comput. Chem., 2013, 69, 87-92.

3. V. Alamian, A. Bahrami and B. Edalatzadeh, Int. J. Mole. Sci., 2008, 9, 229-234.

4. Z. Heping and F. Zhang, Discrete Appl. Math., 1996, 69, 147-167.

5. T. Doslić, J. Math. Chem., 2013, 51, 1599-1607.

6. M. R. Farahani, J. Theor. Chem., 2013, 1, 1-9.

7. E. Deutsch and S. Klavzar, Iran. J. Math. Chem., 2015, 6, 93-102.

8. Y. C. Kwun, M. Munir, W. Nazeer, S. Rafque and S. M. Kang, Sci. Rep., 2017, 7, 8756.

9. M. S. Ahmad, W. Nazeer, S. M. Kang and C.Y. Jung, Global J. of Pure and Appl. Math., 2017, 13, 2749-2776.

10. M. Munir, W. Nazeer, S. Rafique and S. M. Kang, Symmetry, 2016, 8, 149.

11. M. Munir, W. Nazeer, S. M. Kang, M. I. Qureshi, A. R. Nizami and Y. C. Kwun, Symmetry, 2017, 9, 17.

12. S. Mondal, N. De and A. Pal, Commun. Fac. Sci. Univ. Ank. Ser. A1 Math. Stat., 2019, 68, 2104-2116.

13. S. M. Hosamani, J. Appl. Math. Comput., 2017, 54, 425-433.

14. S. Mondal, N. De and A. Pal, J. Mol. Struct., 2021, 1223, 129210.

15. S. Mondal, N. De and A. Pal, Complex Intell. Syst., 2021, https://doi.org/10.1007/s40747-020-00262-0.

16. M. Ghorbani and M. A. Hosseinzadeh, Discrete Math. Algorithms Appl., 2013, 5, 1350039.

17. V. R. Kulli, Int. J. Curr. Resear. Sci. Techn., 2019, 5, 1-14.

18. V. R. Kulli, Ann. Pure and Appl. Math., 2019, 19, 175-181.
19. S. Mondal, N. De and A. Pal, Acta Chem. Iasi, 2019, 27, 31-46.

20. S. Mondal, M. K. Siddiqui, N. De and A. Pal, Biointerface Res. Appl. Chem., 2021, 11, 9372 - 9381.

21. A. Verma, S. Mondal, N. De and A. Pal, Int. J. Math. Trends and Techn., 2019, 65, 83-90.

22. M. Javaid and J. Cao, Neural Comput. Appl., 2017, 30, 3869-3876.

23. J. B. Liu, J. Zhao, S. Wang, M. Javaid and J. Cao, JAISCR, 2018, 8, 257-268.

24. M. Javaid, M. Abbas, J. B. Liu, W. C. Teh and J. Cao, JAISCR, 2019, 9, 111-122.

25. M. Imran, M. K. Siddiqui, A. Q. Baig, W. Khalid and H. Shaker, J. Intell. Fuzzy Syst., 2019, 37, 3605-3614.

26. S. Mondal, N. De and A. Pal, Polycycl. Aromat. Comp., 2020.

27. P. Sarkar, S. Mondal, N. De and A. Pal, Malaya J. Matematik, 2019, 7, 612-617.

28. M. Javaid, A. Raheem, M. Abbas and J. Cao, TWMS J. App. Eng. Math., 2019, 9, 864-875.

29. S. M. Hosamani, D. Perigidad, S. J. Y. Maled and S. Gavade, J. Stat. Appl. Pro., 2017, 6, 1-11.

30. E. V. Konstantinova, J. Chem. Inf. Comput. Sci., 1996, 36, 54-57.

31. T. Tran, T. Nguyen, P. Tsai and X. Kong, Artif. Intell. Rev., 2011, 35, 369-382.

32. T. P. Tran, L. Cao, D. Tran and C. D. Nguyen, Int. J. Comput. Sci. Inf. Secur., 2009, 6, 83-91.

33. L. F. Araghi, H. Khaloozade and M. R. Arvan, In: Proceedings of the international multi conference of engineers and computer scientists, March 18-20, 2009, Hong Kong.

34. S. Meshoul and M. Batouche, In: Proceedings of IEEE symposium on computers and communications, June 2225, 2010, Riccione, Italy (IEEE, New York, 2010), 314319.

35. J. J. Lee and C. B. Yun, KSCE J. Civ. Eng., 2007, 11, 111-120.

36. M. S. Bascil and H. Oztekin, J. Med. Syst., 2012, 36, 1603-1606.

37. F. Budak and E. D. beyli, J. Med. Syst., 2011, 35, 87-91.

38. E. Holmes, J. K. Nicholson and G. Tranter, Chem. Res. Toxicol., 2001, 14, 182-191.

39. Y. Wang, T. Adali, S. Y. Kung and Z. Szabo, IEEE T. Image Process., 1998, 7, 1165-1181.

40. I. B. Standal, J. Rainuzzo, D. E. Axelson, S. Valdersnes, K. Julshamn and M. Aursand, J. Am. Oil. Chem. Soc., 2012, 89, 1173-1182. 